\title{
Escuta afetiva: possibilidades de uso em contextos de acolhimento infantil
}

\author{
Aline Jacob Trivellato \\ Universidade Federal de Mato Grosso do Sul, Campus de Paranaíba - MS \\ Cíntia Carvalho \\ Universidade Federal de Mato Grosso do Sul, Campus de Paranaíba - MS \\ Celia Vectore \\ Universidade Federal de Uberlândia - MG
}

\begin{abstract}
Resumo
O presente estudo teve como objetivo conhecer o processo de acolhimento a partir do relato das crianças acolhidas e de educadoras de uma instituição localizada numa cidade do Interior do Estado do Mato Grosso do Sul. Participaram cinco crianças e cinco educadoras. Para a coleta de dados foram organizadas 27 oficinas com as crianças, que foram divididas em dois grupos, e entrevistas semiestruturadas com as educadoras. Os resultados mostram a importância da escuta atenta às crianças, pois possibilita as narrativas de suas vivências. Quanto às educadoras, observou-se que a interação com as crianças se dá, prioritariamente, nos cuidados básicos. Sugere-se a criação de políticas para a capacitação dessas profissionais, além de estratégias que resgatem a história de vida das crianças acolhidas, já que as rotinas institucionais e a complexidade do processo de acolhimento acabam por desconsiderar esse importante aspecto da construção humana.
\end{abstract}

Palavras-chave: Crianças, abrigos, educadores.

\section{Affective listening: possible uses in childcare contexts}

\begin{abstract}
In this work we study the process of hosting children, based on the reports of children received and on teachers of an institution located in a town in the state of Mato Grosso do Sul. Five children and five teachers were listened to. For data collection we organized 27 workshops with the children, who were divided into two groups, and semi-structured interviews with the teachers. The results show the importance of the careful listening to children, as it allows the narratives of their experiences. Regarding the educators it was observed that interaction with children occurs primarily in basic care. It is suggested the need for policies to train these professionals, and strategies to rescue the life story of the children hosted, since the institutional routines and complexity of host eventually disregard this important aspect of human construction.
\end{abstract}

Keywords: Children, shelters, educators.

\section{Escucha afectiva: posibilidades de uso en contextos de acogida infantil}

\section{Resumen}

Se trata de estudio que tuve como objetivo comprender el proceso de acogida a partir del relato de niños acogidos y de educadoras de una institución ubicada en una ciudad en el interior del Estado de Mato Grosso do Sul. Participaron cinco niños y cinco educadoras. Para la recolección de datos se organizaron 27 talleres con los niños divididos en dos grupos y entrevistas semi-estructuradas con las educadoras. Los resultados muestran la importancia de la escucha atenta a los niños, ya que permite narrativas de sus vivencias. En cuanto a las educadoras se observó que la interacción con los niños se da principalmente en cuidados básicos. Se nota la necesidad de políticas para capacitar a los profesionales, además de estrategias que recuperen la historia de vida de los niños acogidos, una vez que las rutinas institucionales y la complejidad del proceso de acogida acaban ignorando este importante aspecto de la construcción humana.

Palabras clave: Niños, abrigos, educadores. 


\section{Introdução}

Historicamente, desde os períodos da colonização portuguesa até os dias de hoje é possível reconhecer que a infância brasileira, especialmente a das crianças abandonadas, é marcada por episódios ou períodos em que a negligência e os maus-tratos se fazem presentes na rotina de suas vidas. Tal situação, a despeito de iniciativas e políticas,que culminaram com a aprovação do Estatuto da Criança e do Adolescente-ECA (1990) e com a Lei n. ${ }^{\circ} 12.010$, conhecida como Lei Nacional da Adoção (2009), ainda se apresenta de modo expressivo, em nível nacional.

Fatores como pobreza, estrutura familiar constituída de violência física e psicológica, negligência, abandono e dependência química (IPEA, 2004) figuram entre as causas principais que levam ao abandono e, consequentemente, à institucionalização das crianças, quando a família não consegue cumprir sua função básica, representada pela garantia da integridade física e psicológica dos filhos (Lei Nacional da Adoção, 2009). A suspensão do poder familiar ocorre até a situação ser revertida, o que significa o oferecimento dos cuidados primordiais.

A partir de 2009, com a nova Lei Nacional da Adoção, as crianças impossibilitadas do convívio familiar passaram a ser atendidas em instituições de acolhimento, anteriormente denominadas de abrigos. Tais instituições têm como característica principal serem de caráter temporário, já que todos os esforços devem ser empreendidos para possibilitar o retorno ao lar. A complexidade, o histórico e as múltiplas variáveis que se apresentam nessas instituições têm sido amplamente discutidos na literatura pertinente, como nos estudos de Prada, Williams e Weber, (2007), Ayres, Cardoso e Pereira, (2009), Cintra e Souza, (2010) e Nascimento, Lacaz e Travassos (2010), entre outros.

É essencial propiciar um atendimento de qualidade aos acolhidos, pois outras são seres humanos em constante crescimento e formação (Cavalcante, Magalhães, \& Pontes, 2007). Além disso, é necessário criar mecanismos sociais que garantam a provisoriedade da medida (Siqueira \& Dell'Aglio, 2010). Azôr (2005) identificou, em seu estudo em uma instituição de acolhimento, uma permanência média de cerca de 14 anos das crianças e adolescentes ali acolhidos.

Neste contexto, a grande pergunta é: como promover um espaço de qualidade para essas crianças oriundas de situações tão adversas? Responder a essa questão não é tarefa fácil. Estudos anteriores (Carvalho \& Vectore, 2008; Sousa, 2006; Tomás, 2010) têm mostrado quão complexo é o universo das instituições de acolhimento, que enfrentam dilemas básicos, relativos a questões como os vínculos e suas rupturas, o desenvolvimento infantil em espaços coletivos, com poucas possibilidades para a construção de individualidades, a formação insuficiente das mães sociais e/ou educadoras e a própria gestão da instituição, que, se alicerçada em ações desencontradas dos atores responsáveis, pode dificultar o estabelecimento de um perfil institucional adequado.
Com o intuito de lançar luzes nas questões acima referidas, várias ações têm sido descritas na literatura que, se efetivadas em contextos de acolhimento, podem garantir, pelo menos em parte, a qualidade do atendimento a ser dispensado a quem se encontra sob os seus cuidados. Nesse sentido, Nogueira (2011) enfatiza os percalços relativos ao acolhimento de bebês, e Rossetti-Ferreira, Serrano e Almeida (2011) expõem a importância da adequação do relacionamento entre os educadores e os acolhidos, corroborando o argumento de Martins (2005), segundo a qual "o que está em causa é a construção de relações estáveis, contínuas, que tenham significado pessoal para as partes envolvidas e funcionem como referência ou organizador da compreensão que o menor tem do mundo envolvente" (p.8).

A multiplicidade dos aspectos ou contextos presentes no acolhimento influencia a vivência institucional da criança acolhida. A interação de tais fatores e os seus impactos podem ser compreendidos pela visão sistêmica adotada na Teoria Bioecológica do Desenvolvimento Humano de Bronfenbrenner (Bronfenbrenner, 1996; Bronfenbrenner \& Ceci, 1994; Bronfenbrenner \& Morris, 1998) e explicitada para contextos de acolhimento por Rosa, Santos, Melo e Souza (2010), Siqueira e Dell'Aglio (2006) e Yunes, Miranda e Cuello (2004).

A partir da perspectiva acima apontada, a criança acolhida pertence diretamente ao microssistema, que no caso é a instituição de acolhimento (Yunes e cols., 2004), que está sujeita a interferência de contextos mais abrangentes, pertencentes ao macrossistema, ao mesossistema e ao exossistema (Bronfrenbrenner, 1996). Ademais, pela fragilidade de dessas instituições, que não têm "voz", muitas vezes o que ocorre é o acolhimento inadequado, o qual reproduz o abandono anteriormente sofrido.

De fato, várias inadequações podem ser observadas nos espaços de acolhimento, entre elas a inexistência ou a insuficiência de momentos propiciadores do afloramento da subjetividade infantil, que pode ser manifestada pelas múltiplas linguagens disponíveis à criança (Malaguzzi, 2007), como a ludicidade, o contar e o recontar de histórias, entre outras. Por outro lado, a ampla literatura psicológica, em suas diferentes abordagens, mostra o descompasso entre esse cotidiano restrito e as possibilidades efetivas do desenvolvimento global e harmonioso do ser humano (Bruner, 1999; Piaget, 1970; Vygotsky, 2007; Wallon, 1968).

A despeito das suas dificuldades e complexidades, as instituições de acolhimento podem ser contextos de desenvolvimento humano, conforme estudos já relatados (Azôr, 2005; Rosa e cols., 2010). Para tanto, uma das possibilidades seria a mudança de paradigma na compreensão da criança acolhida, passando do enfoque das suas carências para o de suas potencialidades. Entender as crianças como capazes, escutá-las e dar voz às suas experiências são atitudes que podem contribuir para a manifestação de aspectos importantes da sua subjetividade e ser um ponto de partida para intervenções promotoras do desenvolvimento infantil. 
A Escuta Psicológica, regulamentada pela Resolução CFP N. ${ }^{\circ}$ 010/2010, é um instrumento pertinente para o trabalho das instituições de acolhimento. Andrade e Morato (2004) argumentam que "a garantia do espaço de escuta como lugar para a subjetividade na instituição pode, pela transformação de seus participantes, levar a transformações institucionais" (p. 352).

Diante do exposto, tem-se que o presente estudo se justifica pelo fato de que, ao propor atividades lúdicas atreladas a uma escuta sensível, aqui denominada de escuta afetiva, pela possibilidade de acolhimento das falas das crianças, sem preconceitos, julgamentos e interpretações de quem ouve (Barbier, 2002), foi possível conhecer as histórias e singularidades das crianças institucionalizadas (Arpini, 2003; Marmelstejn, 2006; Tinoco, 2001), além de reconhecer as particularidades e necessidades das educadoras.

\section{Método}

Caracterização da instituição de acolhimento

Os dados foram coletados em uma instituição que mantém acolhidas dez crianças. O número de acolhidos pode variar para mais ou para menos, pela transitoriedade característica destas instituições. A rotina das educadoras envolve cuidados com as crianças, com ênfase na alimentação e higiene, além da limpeza da casa e das roupas, entre outros aspectos da vida em instituições desse tipo.

A rotina institucional é organizada considerando-se o horário escolar, compreendido pelos períodos matutino e vespertino. Assim, após a chegada da escola, as crianças tomam banho, jantam, assistem televisão e dormem por volta das sete e trinta da noite.

As crianças recebem, esporadicamente, visitas de pessoas da comunidade; as da família são comumente esperadas aos sábados, das 13 às 16 horas. Aos domingos não há atividades direcionadas pelas educadoras ou outros profissionais e raras veze as crianças são levadas para passear fora da instituição.

\section{Participantes}

Participaram deste estudo cinco crianças de idade entre quatro e nove anos, divididas em dois grupos: o grupo 1 (João e Maria) e o grupo 2 (Calvin, Cindy e Tina); e cinco educadoras, com idade entre 38 e 62 anos e experiência na função variável de dez até menos de um ano, oriundas de uma instituição de acolhimento localizada em uma cidade do Interior do Estado do Mato Grosso do Sul.

\section{Instrumentos}

Para a coleta de dados foram utilizados os seguintes instrumentos:
- Entrevistas semiestruturadas com as educadoras, visando explorar entre outros, os seguintes aspectos: formação; experiência e/ou treinamento para o exercício da função; facilidades e dificuldades encontradas no exercício profissional; percepção das crianças acolhidas.

- Observações da rotina institucional: realizadas na instituição, por meio de registros cursivos de dois períodos, matutino e vespertino, num total de oito horas.

- Contos de Fadas dos Irmãos Grimm: Branca de Neve, João e Maria, Rapunzel, Sete Corvos, além de outras histórias infantis, como Chapeuzinho Amarelo (Chico Buarque), Mania de Explicação (Adriana Falcão), A menina e o pássaro encantado (Rubem Alves). Esclarece-se que a escolha do trabalho com os contos de fadas se justifica por ser este um importante recurso de promoção da identificação das crianças com alguns personagens, o que contribuiu para a protagonização de suas vivências. As crianças podem se tornar protagonistas pelo desvio que fazem do esperado da história, direcionando a narrativa para situações da própria vida. Trata-se do "desvio da canonicidade quando as crianças usam expressões que Ihes chamam atenção para recriar novas situações, transformando a cultura do adulto em cultura infantil" (Kishimoto, 2007, p. 440), por meio da aprendizagem.

- Atividades lúdicas: baseadas prioritariamente nas sugestões presentes no material do Instituto Fazendo História (2008), como "Carteira de Identidade", "Descobrindo minhas medidas", "Medo, medinho, medão", "São tantas emoções”, "Pessoinha”, “Jamais Esquecerei”, “Árvore genealógica", "Casinha Feliz", "Repórter por um dia", "Sonhos", entre outras.

- Álbuns: construídos junto às crianças e organizados com capa de material resistente, folhas em branco para registrar acontecimentos, vivências, fotos, historinhas, desenhos, gravuras, colagens, incluindo informações como seus dados pessoais, os dados dos familiares, dos amigos, da instituição e da escola, fotos legendadas de familiares, amigos e educadoras; brincadeiras preferidas, depoimentos de pessoas significativas, motivo do acolhimento, lembranças significativas; perspectivas futuras, etc. A importância deste instrumento está na possibilidade de registrar, com a autorização e parceria das crianças, aspectos referentes à sua própria história. Cada registro proporciona uma experiência única de manifestação da subjetividade infantil, como enfatiza o Instituto Fazendo História (2008). Neste estudo, foi estabelecido que cada álbum deveria permanecer com a criança ou ser-Ihe entregue no momento da desinstitucionalização.

\section{Procedimentos 1}

A coleta de dados teve início na instituição após autorização do juiz responsável pela Vara da Infância e Juventude, o consentimento do responsável legal pela instituição - no caso, a Secretaria de Assistência Social do município -, a aprovação do Comitê de Ética em Pesquisa 
da Universidade Federal do Mato Grosso do Sul (protocolo n. ${ }^{\circ} 1914$ CAAE 0004.0.049.000-11) e a assinatura do Termo de consentimento Livre e Esclarecido pelos participantes e responsáveis. Todos os dados descritos neste estudo foram coletados entre outubro de 2010 e maio de 2011.

Após a definição dos participantes, as crianças foram divididas em dois grupos - grupo 1 e grupo 2 -, sendo realizadas vinte e sete oficinas com cada um, com duração média de uma hora. As oficinas ocorreram aos domingos e consistiram de ações promotoras de uma vinculação adequada entre a pesquisadora e os participantes, a partir do uso de brincadeiras e jogos diversos, leituras de histórias infantis e dramatizações. Sinteticamente, foram tratados os seguintes temas: preferências diversas das crianças; vínculos, por meio da escrita de uma carta escrita a uma pessoa querida; construção da identidade; vivências durante o processo de acolhimento; representações quanto ao futuro, sonhos, desejos, visão de si. Todas as atividades foram registradas pelas crianças, com o auxílio da pesquisadora, com vistas à produção do álbum de cada participante, com as suas histórias, fragmentos e subjetividades. As oficinas foram audiogravadas para posterior transcrição e análise dos dados.

\section{Resultados}

Após a realização das atividades na instituição - especialmente as entrevistas com as educadoras e as oficinas com as crianças -, foram realizadas as transcrições e a análise minuciosa dos dados obtidos, cujo conteúdo (Bardin, 2008) possibilitou o reconhecimento de algumas categorias, que serão descritas a partir de dois blocos identificados, como: 1. Entrevista com as educadoras, e 2. Atividades com as crianças.

\section{Entrevista com as educadoras}

Os dados oriundos das entrevistas com as educadoras podem ser contemplados a partir das seguintes dimensões: (a) Formação e contratação para a função de educadora; e (b) Percepções do trabalho: facilidades e desafios. cadora

(a) Formação e contratação para a função de edu-

Todas as educadoras do estudo já tinham experiência em cuidar de crianças, devido a empregos anteriores como babá, merendeira, etc., mas mão tinham nenhuma qualificação ou capacitação em serviço para o trabalho com acolhidos. Entre os critérios mencionados para a contratação estavam gostar de crianças e manter sigilo quanto aos acontecimentos da casa, conforme se depreende das falas abaixo:

Pesquisadora: Teve alguma exigência para trabalhar na instituição?

Educadora 4: Aqui não, a única coisa que disseram é que tinha que gostar muito de criança, que não podia bater.
Educadora 2: Teve, a única exigência que eles fez (sic) foi que, o que entrá (sic) aqui, fica aqui, entendeu?

É importante destacar que gostar de crianças, independentemente de se ter a formação necessária para o exercício da função, não se traduz necessariamente no oferecimento de um atendimento de qualidade. A Lei $\mathrm{N} .^{\circ}$ 7.644, de 18 de dezembro de 1987, prevê o treinamento de educadores e mães sociais em abrigos. De acordo com a referida lei, mães sociais são mulheres contratadas para trabalhar em casas-lares que acolham no máximo dez crianças, oportunizando assim condições semelhantes às de uma residência comum e de uma convivência familiar. Nenhuma educadora do presente estudo conhecia tal lei.

(a) Percepções do trabalho: desafios e prazeres

No tocante à maneira como percebem os seus trabalhos, foi possível constatar que algumas educadoras manifestam sentimentos de menoscaso e tristeza, relativos à pouca valorização dada pela instituição, conforme o excerto abaixo:

Pesquisadora: A senhora sente que seu trabalho é valorizado?

Educadora 3: Não. Não. Não.

Pesquisadora: Por que a senhora acha isso?

Educadora 3: Porque eu acho que a gente precisa ter mais apoio. Porque todo mundo que fica de fora acha fácil, mas não é! (começa a chorar).

Além dos sentimentos acima mencionados, as educadoras se queixam do modo como é conduzida a gestão da instituição, que permite a exacerbação de conflitos interpessoais oriundos do não cumprimento de horários, de divisões julgadas injustas das tarefas, etc., sem o devido encaminhamento, conforme fragmento abaixo:

Pesquisadora: A senhora gostaria de falar mais alguma coisa?

Educadora 2: querê (sic) eu queria, que mudasse outros funcionários aqui. Mas não tem jeito! (...) A pessoa entra aqui e fala: "Ah, eu adoro criança! Nossa, eu tenho paixão por criança”, depois que entra aqui, não quer saber de nada com as crianças. Aqui tem que trabalhá (sic) gente forte mesmo. Eu sei que... não é fácil, tem que ter vontade!

As educadoras relatam prazer em trabalhar com crianças, principalmente com os bebês, além do gosto em limpar a casa, cuidar da alimentação e da higiene das crianças, mas mencionam a necessidade de oferecer cuidados que preservem a singularidade das crianças, o que não é considerado no contexto estudado, segundo se observa na fala abaixo:

Pesquisadora: Acha que a casa acolhe as particularidades de cada criança? As coisinhas que ela tem e que são só dela? 
Educadora 1: Não (...) as coisinhas delas não têm separação, as roupa não têm separação, se serve na outra, veste (...). Mas eu não acho muito certo.

\section{Atividades com as crianças}

A partir dos relatos das crianças foi possível identificar a ocorrência de dimensões envolvendo o processo de acolhimento, como: (a) Apreço pelas atividades proporcionadas pelas oficinas; (b) Conflitos; (c) Protagonização das crianças, detalhadas abaixo. oficinas

(a) Apreço pelas atividades proporcionadas pelas

No que tange às oficinas realizadas, os dados indicam uma expressiva adesão das crianças a essas atividades, conforme se depreende da fala abaixo:

João: por que você só vem de domingo?

Pesquisadora: porque em dia de semana vocês têm aula.

João: não, por que você não vem de sábado e domingo pra fazê (sic)? (Oficina 15 - Grupo 1)

\section{(b) Conflitos}

Os conflitos entre os participantes ocorreram principalmente pela divergência de ideias e divisão de materiais. Houve situações de disputa, ora com agressões físicas, ora com agressões verbais, como pode ser observado a seguir:

Pesquisadora: Tina, a cola é dos três.

Tina: é só pra um.

Pesquisadora: não é não. Tem que dividir.

Tina: não divide. (Oficina 22 - Grupo 2)

Pesquisadora: que cor que você quer?

Maria: eu quero esse amarelo.

João: então vai tomá (sic) no cu! (Oficina 24- Grupo 1)

Pesquisadora: e agora aqui? O que quer que eu escreva?

João: vou dá um pau na Maria, que vou deixá (sic) ela de cama.

Pesquisadora: o que quer que eu escreva?

Maria: meu melhor lugar.

(João começa a bater em Maria)

Maria: para!

Pesquisadora: João, não! Você está machucando ela. Por que faz isso? Machuca, João! Por que você está nervoso? Eu sei que às vezes a gente fica nervoso com alguma coisa, mas se bater, pode machucar! (João para de bater)- (Oficina 20 - Grupo 1)

(c) Protagonização das crianças

A protagonização das crianças pode ser observada nos registros dos seus desenhos, nas histórias por elas recontadas e em outras atividades realizadas, em que puderam narrar espontaneamente aspectos de seus sentimentos e suas vivências cotidianas na instituição de acolhimento e no contexto familiar.

Em relação à vivência na instituição de acolhimento, observa-se:

Pesquisadora: E como você se sentiu quando entrou aqui na casa?

João: ruim

Pesquisadora: por que ruim?

João: porque é muito ruim tá (sic) trancado aqui, não podê (sic) ir na rua pra brincá (sic)... (Oficina 21 Grupo 1)

Por outro lado, no que concerne à vivência em contexto familiar, podem se constatar as dificuldades enfrentadas pelas crianças, expostas a um ambiente com drogas ilícitas e à violência doméstica, conforme se depreende dos excertos abaixo:

Pesquisadora: a maconha é uma planta.

João: daí planta, seca e faz o negócio lá.

Pesquisadora: você conhece?

João: eu não. Já vi.

Pesquisadora: já viu? Onde?

João: na minha casa. Não é? (pedindo confirmação de Maria)

Pesquisadora: na sua casa? E o que você achava disso?

João: eu não achava nada.

Maria: aí a gente cherava (sic) aquele cheiro fazia até mal. (Oficina 12 - Grupo1)

Tina: sabe por que eu não fui lá? Porque quando eu tava com a minha mãe, quando eu vim pro abrigo, minha mãe tinha me batido.

Pesquisadora: Ah é? E aí? Como foi isso?

Tina: ela bateu aqui, ó (próximo ao olho)- (Oficina 17

- Grupo 2)

\section{Discussão}

A compreensão do universo infantil estudado foi possibilitada pelo conhecimento e entendimento do ambiente institucional no qual as crianças estavam inseridas, conforme indica a Teoria Bioecológica do Desenvolvimento Humano de Bronfenbrenner (Bronfenbrenner, 1996). Isto permite refletir sobre a importância de a instituição possuir o seu histórico, a sua identidade, os seus objetivos no atendimento às crianças, pois tais dados possibilitam um melhor esclarecimento das formas estruturais e relacionais adotadas no seu funcionamento (Gulassa, 2006).

Embora a instituição mantenha uma estrutura física adequada para o acolhimento infantil, ajustando-se aos padrões estabelecidos pelo IPEA (2004), com delimitações 
definidas (quarto, sala, cozinha, banheiros, etc.), observa-se ainda a necessidade de um espaço e de acomodações suficientes para garantir o atendimento personalizado, o relacionamento interpessoal ininterrupto e projetos de ações dirigidos a cada acolhido, conforme enfatiza Oliveira (2006). Acrescenta-se ainda a importância de se garantir que a individualidade e a subjetividade não sejam diluídas em um contexto em que tudo é de todos e nada é de ninguém. Tal fator se constitui como um dos requisitos para um acolhimento de melhor qualidade para as crianças.

Nesse sentido, embora os profissionais encarregados do cuidado infantil gostem e tenham prazer boa vontade no cuidado às crianças, falta ainda compreensão acerca do desenvolvimento infantil. Como as crianças estão em situação de acolhimento e apartadas de seus responsáveis, o acolhimento deve não somente atende às necessidades físicas, mas também abranger todos os outros aspectos necessários à construção humana, especialmente os psicológicos, já que as crianças tendem a repetir nas relações institucionais suas vivências anteriores de abandono (Marques, Cano, \& Vendruscolo, 2007). Carvalho e Manita (2010) apontam como fonte de insatisfação entre os acolhidos a impossibilidade de terem ao seu alcance objetos pessoais. Além disso, Negrão e Constantino (2011) alertam que muitas ações engendradas no contexto institucional fragilizam ou impedem a emancipação dos acolhidos.

Os resultados indicam o pouco destaque dado à formação profissional, quer como critério a ser considerado na contratação das educadoras, quer como iniciativas para a capacitação em serviço dessas profissionais. O que se tem é a ênfase no "gostar de crianças", independentemente da formação para devidamente atendê-las, desconsiderando-se as exigências éticas e técnicas e o perfil pessoal (aspectos emocionais) necessários para o exercício adequado da função, segundo esclarece Teixeira (2011). Além disso, Costa e Rossetti-Ferreira (2009) alertam para a necessidade de pensar diversas formas de acolhimento, capazes de garantir a "qualidade de ambientes, de pessoal, de capacitação inicial e em serviço, de conhecimentos técnicos, etc." (p.117).

Em síntese, a capacitação deve permitir a desconstrução do conceito idealizado e romantizado da infância, permitindo que os profissionais possam lidar com comportamentos difíceis apresentados pelas crianças. Tais comportamentos podem ser observados nas falas e as ações de João, que, ao expressar seus ressentimentos, demonstra seus poucos recursos relacionados às habilidades sociais, acabando por exacerbar os conflitos existentes naquele espaço institucional.

Em se tratando das atividades realizadas junto às crianças, priorizou-se o trabalho com grupos pequenos, para proporcionar maior integração com a pesquisadora. Esta ação possibilitou uma maior atenção às crianças e o aparecimento e solução de possíveis conflitos entre elas (Cruz, 2010; Oliveira-Formosinho, 2008).

De fato, o adequado manejo dos conflitos possibilita a transformação dos relacionamentos, por meio da negociação e da consideração de diferentes pontos de vista que são importantes para o desenvolvimento infantil pela capacidade de vislumbrar outras perspectivas, além de suas próprias (Rinaldi, 1999). Não obstante, Barros e Fiamenghi (2007) lembram que as crianças acolhidas estão, normalmente, expostas a um número maior de situações geradoras de agressividade, por serem obrigadas a conviver rotineiramente com outras crianças e, desde muito cedo, precisarem resguardar o que é seu, como os brinquedos, os sentimentos e até mesmo a própria vontade, o que evidencia a importância de uma adequada mediação dos conflitos infantis pelo adulto nesses contextos.

No que diz respeito à escuta afetiva, sensível, de caráter empático e sem julgamentos (Barbier, 2002), os dados mostram que os participantes a exercitam de modo adequado. As educadoras sentiram-se à vontade para relatar suas vivências e dificuldades e expressar os sentimentos relacionados ao trabalho. Neste sentido, é importante destacar que houve vários momentos de choro, o que sugere a necessidade de um espaço apropriado para tais manifestações, baseado em um efetivo trabalho pela ou com a equipe técnica da instituição. Daí decorre a necessidade de capacitar todos os profissionais atuantes nesses contextos.

Em relação às crianças, no início se portaram de modo defensivo, com comportamentos sugestivos de desconfiança, próprios da insegurança dos primeiros contatos; entretanto, ao se vincularem adequadamente com a pesquisadora, manifestaram liberdade em expressar-se, brincar e falar de momentos bons e dolorosos de suas vivências. Além disso, embora não tenha sido o objetivo do estudo quantificar os comportamentos exibidos pelas crianças, observou-se que, ao longo das oficinas, houve uma diminuição dos conflitos, maior respeito às regras durante as atividades e o apreço pela construção do álbum de sua história, demonstrando o gosto das crianças em mostrá-lo às outras pessoas e contar-lhes um pouco de sua própria vida.

Malaguzzi (1999) afirma que o trabalho junto à criança deve possibilitar o sentimento de prazer na realização das atividades, na investigação de suas hipóteses e, principalmente em se perceberem como protagonistas em suas realizações. Assim, as brincadeiras, as atividades mediadas pela literatura infantil e os recursos mediacionais (Vectore, 2011) podem contribuir com intervenções psicológicas capazes de fazer aflorarem as subjetividades, aspecto fundamental e não raras vezes negligenciado em contextos de acolhimento.

\section{Considerações finais}

Conhecer as interações tecidas numa instituição de acolhimento a partir das vivências das crianças e das educadoras mostrou a complexidade e a multiplicidade de variáveis que estão presentes nesse contexto, além de lançar luzes sobre a necessidade contínua de intervenções direcionadas tanto para quem trabalha quanto para quem recebe os cuidados. Para tanto, é importante considerar desde a integração entre a rede de cuidado à infância, muitas 
vezes desarticulada por diferentes motivos, e os cuidados que deveriam estar focados na qualidade do atendimento às crianças, o qual exige, entre outras coisas, a formação, o acompanhamento do trabalho das educadoras, pois algumas formas de "educar" estão emaranhadamente associadas às suas vivências socioafetivas e educacionais singulares e não podem ser desconsideradas, conforme já afirmaram estudos anteriores (Gulassa, 2010; Sousa, 2006).

No caso da escuta realizada com as crianças, o álbum personalizado, as atividades e narrativas infantis demonstraram ser importantes instrumentos de expressão de conteúdos singulares daquelas crianças, devido à possibilidade de identificar elementos por vezes perdidos que, por isso mesmo, é importante preservar durante o processo de acolhimento institucional (Instituto Fazendo História, 2008). Alguns aspectos das produções realizadas no álbum demonstraram baixa autoestima, insegurança emocional ou dificuldades específicas, como na escrita, o que sugere a necessidade de um acompanhamento mais efetivo das condições e dificuldades enfrentadas pelas crianças na escola, encorajando-as a desenvolver vínculos positivos quanto à construção da língua escrita.

No desenrolar das oficinas junto às crianças, dados referentes à sua história familiar e escolar não puderam ser inseridos em seus álbuns, devido à indisponibilidade ou inexistência de registros. É importante salientar a importância dessas informações para a construção de um ser humano, já que se trata de um sujeito histórico.

O trabalho ora relatado destaca a necessidade de novos estudos para uma compreensão mais abrangente do processo de desenvolvimento em ambientes coletivos. Além disso, é necessário criar e adotar políticas públicas que possam efetivamente contribuir para a formação e reconhecimento de educadoras e mães sociais, de maneira a terem nessa profissionalização condições dignas de sobrevivência.

Por fim, destaca-se a necessidade de formação da equipe multiprofissional para o devido atendimento e entendimento do processo de acolhimento, com conteúdos capazes de abarcar a multiplicidade e complexidade de aspectos que se apresentam em tal processo. Em especial, acredita-se que os cursos de graduação em Psicologia, principalmente os que tenham como ênfase a formação do psicólogo escolar e educacional, devem estar atentos a essa inserção, com disciplinas que contemplem a legislação e as políticas públicas relacionadas à infância, como por exemplo, o conhecimento do Estatuto da Criança e do Adolescente, as propostas do SUAS (Sistema Único de Assistência Social) e do PNCFC (Plano Nacional de Convivência Familiar e Comunitária), entre outros procedimentos. Vale ainda destacar a iniciativa do Conselho Regional de Psicologia - $6^{a}$ Região, de promover fóruns de debate sobre a atuação dos psicólogos nos serviços de acolhimento institucional para crianças e adolescentes, pois contribui com práticas cada vez mais pertinentes, visando à melhoria da qualidade no atendimento às crianças institucionalizadas.

\section{Referências}

Arpini, M. (2003). Repensando a Perspectiva Institucional e a Intervenção em Abrigos para Crianças e Adolescentes. Psicologia Ciência e Profissão, 21(3), 70-75.

Andrade, A. N., \& Morato, H. T. P. (2004). Para uma dimensão ética da prática psicológica em instituições. Estudos de Psicologia, 9(2), 345-353.

Ayres, L. S. M., Cardoso, A. P., \& Pereira, L. C.(2009). O abrigamento e as redes de proteção para a infância e a juventude. Fractal: Revista de Psicologia, 21(1), 125-136.

Azôr, A. M. G. C. C. V. (2005). Abrigar, desabrigar: conhecendo o papel das famílias no processo de institucionalização/ desintitucionalização de abrigados. Dissertação de Mestrado, Universidade Federal de Uberlândia, Uberlândia, Minas Gerais.

Barbier, R. (2002). Escuta sensível na formação de profissionais de saúde. Recuperado: 20 nov 2011. Disponível: http://www.saude. df.gov.br/FEPECS.

Bardin, L. (2008). Análise de conteúdo. Lisboa: Edições 70.

Barros, R. C., \& Fiamengui Jr., G. A. (2007). Interações afetivas em crianças abrigadas: um estudo etnográfico. Ciência e Saúde Coletiva, 12(5), 1267-1276.

Bronfenbrenner, U. (1996). A ecologia do desenvolvimento humano: experimentos naturais e planejados. Porto Alegre: Artes Médicas.

Bronfenbrenner, U., \& Ceci, S. J. (1994). Nature-nurture reconceptualized in developmental perspective: a bioecological model. Psychological Review, 101, 568-586.

Bronfenbrenner, U., \& Morris, P. (1998). The ecology of developmental processes. Em W. Damon (Org.), Handbook of child psychology (Vol.1, pp. 993-1027). New York: John Wiley \& Sons.

Bruner, J. S. (1999). Concepções de infância: Freud, Piaget, Vigostki. Recuperado: 20 abr 2012. Disponível: http://www.4shared.com/ get/5Vng_tv/

Carvalho, T., \& Manita, C. (2010). Percepções de Crianças e Adolescentes Institucionalizados sobre o Processo de Institucionalização e a Experiência na Instituição. Actas do VII Simpósio Nacional de Investigação em Psicologia. Universidade do Minho, Portugal.

Carvalho, C., \& Vectore, C. (2008). Um olhar sobre o abrigamento: a importância dos vínculos em contexto de abrigo. Revista Psicologia Escolar e Educacional, 12(2), 441-449.

Cavalcante, L. I. C., Magalhães, C. M. C., \& Pontes, F. A. R. (2007). Abrigo para crianças de 0 a 6 anos: um olhar sobre as diferentes concepções e suas interfaces. Mal-Estar e Subjetividade, 2, 329 
$-352$.

Cintra, A. L., \& Souza, M. (2010). Institucionalização de crianças: leituras sobre a produção da exclusão infantil, da instituição de acolhimento e da prática de atendimento. Revista Mal-Estar e Subjetividade, $X(3)$, 809-833.

Resolução CFP No 010. (2010). Institui a regulamentação da Escuta Psicológica de Crianças e Adolescentes envolvidos em situação de violência, na Rede de Proteção. Brasília, DF.

Conselho Regional de Psicologia - $6^{\mathrm{a}}$ região. (2011). Fórum de debate sobre a atuação dos psicólogos nos serviços de acolhimento institucional para crianças e adolescentes. Recuperado: 5 set 2012. Disponível: http://www.crpsp.org.br/acolher/.

Costa, N. R. A., \& Rossetti-Ferreira, M. C. (2009). Acolhimento Familiar: Uma Alternativa de Proteção para Crianças e Adolescentes. Psicologia: Reflexão e Crítica, 22(1), 111-118.

Cruz, S. H. V. (2010). Ouvir crianças: uma tarefa complexa e necessária. Em M. P. R. de Souza (Org.), Ouvindo crianças na escola: abordagens e desafios metodológicos para a psicologia. São Paulo: Casa do Psicólogo.

Gulassa, M. L. C. R. (2006). A fala dos abrigos. Em M. V. Baptista (Coord.), Abrigo: comunidade de acolhida e socioeducação. São Paulo: Instituto Camargo Corrêa.

Gulassa, M. L. C. R. (2010). Abrigos em movimento. São Paulo: Instituto Fazendo História: NECA.

Instituto de Pesquisa Econômica Aplicada. (2004). Os abrigos para crianças e adolescentes e o direito à convivência familiar e comunitária. Brasília: Autor.

Instituto Fazendo História. (2008). Fazendo minha história: Guia de ação para abrigos e colaboradores. São Paulo: Autor.

Kishimoto, T. M. (2007). Brincadeiras e narrativas infantis: contribuições de J. Bruner para a pedagogia da infância. Em J. Oliveira-Formosinho, T. M. Kishimoto \& M. P. Pinazza (Orgs.), Pedagogia(s) da Infância: Dialogando com o Passado: Construindo o Futuro. Porto Alegre: Artmed.

Lei n. 7.644, de 18 de dezembro de 1987. (1987). Dispõe sobre a regulamentação da atividade de Mãe Social e dá outras providências. Recuperado: 05 mar 2012. Disponível: https:// www.planalto.gov.br/ccivil_03/Leis/L7644.htm

Lei n. 8069, de 13 de julho de 1990. (1990). Estatuto da criança e do adolescente. Brasília: Diário Oficial da União.

Lei n. 12.010, de 3 de agosto de 2009. (2009). Dispõe sobre adoção e dá outras providências. Recuperado 05 mar 2012. Disponível: http://www.planalto.gov.br/ccivil_03/
Malaguzzi, L. (1999). História, Ideias e Filosofia Básica. Em C. Edwards , L. Gandini \& G. Forman As Cem Linguagens da Criança: A Abordagem de Reggio Emilia na Educação da Primeira Infância (pp. 59-104). Porto Alegre: Artmed.

Malaguzzi, L. (2007). Ao contrário, as cem existem. Em A. L. G. de Faria \& M. S. Palhares (Orgs.), Educação Infantil pós - LDB: Rumos e desafios (6a ed.). Campinas, SP: Autores Associados.

Marmelsztejn, R. (2006). Psicoterapia para crianças e adolescentes abrigados: Construindo uma forma de atuação. Dissertação de Mestrado, Pontifícia Universidade Católica de São Paulo, São Paulo-SP.

Marques, C. M. L., Cano, M. A. T., \& Vendruscolo, T. S. (2007). A percepção dos educadores sociais de crianças em abrigos em relação ao processo de cuidar. Serviço Social \& Realidade, 16(2), 22-41.

Martins, P. C. (2005). O desenvolvimento pessoal e social da criança em contexto de vida institucional: elementos para uma análise da ecologia da interpessoalidade. Actas do Congresso Inadaptação Social: transformações, intervenção e avaliação. Porto, Portugal.

Nascimento, M. L., Lacaz, A. S., \& Travassos, M. (2010). Descompassos entre a lei e o cotidiano nos abrigos: percursos do ECA. Aletheia, 31, 16-25.

Negrão, A. V. G., \& Constantino, E. P. (2011). Acolhimento institucional em tempos de mudança. São Paulo: Unesp.

Nogueira, F. (2011). Entre o singular e o coletivo: o acolhimento de bebês em abrigos. São Paulo: Instituto Fazendo História.

Oliveira, R. C. (2006). A história começa a ser revelada: Panorama atual do abrigamento no Brasil. Em M. V. Baptista (Coord.), Abrigo:comunidade de acolhida e socioeducação. São Paulo: Instituto Camargo Corrêa.

Oliveira-Formosinho, J. (Org.) (2008). A escola vista pelas crianças. Porto, Portugal: Porto Editora.

Prada, C. G., Williams, L. C. A., \& Weber, L. N. D. (2007). Abrigos para crianças vítimas de violência doméstica: funcionamento relatado pelas crianças e pelos dirigentes. Psicologia: Teoria e Prática, $9(2), 14-25$.

Piaget, J. (1970). Epistemologia Genética. Petrópolis, RJ: Vozes.

Rinaldi, C. (1999). O Currículo Emergente e o Construtivismo Social. Em C. Edwards, L. Gandini \& G. Forman, As Cem Linguagens da Criança: A Abordagem de Reggio Emilia na Educação da Primeira Infância. Porto Alegre: Artmed.

Rosa, E. M., Santos, A. P., Melo, C. R. S., \& Souza, M. R.(2010). Contextos ecológicos em uma instituição de acolhimento para crianças. Estudos de Psicologia (Natal), 15(3), 233-241. 
Rossetti-Ferreira, M. C., Serrano, S. A., Almeida, I .G (Orgs.). (2011) O Acolhimento Institucional na Perspectiva da Criança. São Paulo: Hucitec.

Siqueira, A. C., \& Dell'Aglio, D. D. (2006). O impacto da institucionalização na infância e na adolescência: uma revisão da literatura. Psicologia \& Sociedade, 18(1), 71-80.

Siqueira, A. C., \& Dell'Aglio, D. D. (2010). Crianças e adolescentes institucionalizados: desempenho escolar, satisfação de vida e rede de apoio social. Psicologia: Teoria e Pesquisa, 26(3), 407-415.

Sousa, A. R. R. (2006). Abrigar... brincar: um estudo sobre as vivências lúdicas entre educadoras e crianças de um abrigo. Dissertação de Mestrado, Universidade Federal de Uberlândia, Uberlândia-MG.

Teixeira, M. L. T. (2011). A Supervisão Institucional nos serviços de acolhimento para crianças e adolescentes: política de capacitação e gestão do trabalho no âmbito do SUAS. Fórum de Debate "A atuação dos psicólogos nos serviços de acolhimento institucional para crianças e adolescentes". São Paulo: CRP/06.

Tinoco, V., \& Franco, M. H. P. (2011). O luto em instituições de abrigamento de crianças. Estudos de Psicologia, 28(4), 427-434.
Tomás, D. N. (2010). Conhecendo o perfil mediacional das mães sociais: um estudo sobre as interações em abrigos. Dissertação de Mestrado, Universidade Federal de Uberlândia, UberlândiaMG.

Vectore, C. (2011). Estratégias mediacionais: possibilidades de inserção do psicólogo escolar/educacional em abrigos. Em A. M. Martinez (Org.), Psicologia escolar e compromisso social. Campinas, SP: Alínea.

Vygotsky, L. S. (2007). A formação social da mente (7a ed.). São Paulo: Martins Fontes.

Wallon, H. (1968). A evolução psicológica da criança. São Paulo: Martins Fontes.

Yunes, M. A. M., Miranda, A. T., \& Cuello, S. E. S. (2004). Um olhar ecológico para os riscos e as oportunidades de desenvolvimento de crianças e adolescentes institucionalizados. Em S. H. Koller (Org.), Ecologia do desenvolvimento humano: pesquisa e intervenção no Brasil (pp. 197-218). São Paulo: Casa do Psicólogo.

\section{Sobre as autoras}

Recebido em: 13/06/2012

Reformulado em: 03/10/2012

$19 / 11 / 2012$

Aprovado em: 29/11/2012

Aline Jacob Trivellato (li_trivellato@hotmail.com)

Universidade Federal de Mato Grosso do Sul, Campus de Paranaíba, graduação em Psicologia

Rua: José Fernandes Rodrigues Filho, n. 10, Cohab Gaspar P. da Fonseca, Aspásia/SP, CEP: 15763-000.

Cíntia Carvalho (cintiacarvalhoufms@gmail.com)

Universidade Federal de Mato Grosso do Sul, Campus de Paranaíba, mestre em Psicologia.

Rua: José Batista de Camargo, 830. Bairro: Jardim Redentora, Paranaíba/MS, CEP: 79500-000.

Celia Vectore (vectore@ufu.br)

Universidade Federal de Uberlândia, doutora em Psicologia.

Rua: Delmira Cândida Rodrigues da Cunha, 1279, bairro Santa Mônica, Uberlânida/MG,

CEP: 38408-208 